\title{
Validated Instruments for Children and Adolescents with Chronic Disease: an Integrative Review
}

\author{
Araújo YB ${ }^{1}$, Santos $\mathrm{SR}^{2}$, Bezerra $\mathrm{TA}^{3}{ }^{3}$, Lima $\mathrm{DM}^{4}$, \\ Mello MN $^{5}$, Neves NTAT 6 , Nascimento JA ${ }^{7}$
}

\section{Abstract}

Objective: Conduct a survey of scientific articles that aim the validation of instruments for children and adolescents with chronic disease.

Method: An integrative review, built in August 2015, using the virtual libraries PubMed and SciELO, and as keywords children, adolescents, chronic illness, validation studies and data collection, published in the Spanish, English, French or Portuguese languages, during the period June 2004 to June 2015.

Results: Were found 16 articles that met the inclusion criteria.

Discussion: The construction of the summary of selected studies shows that the creation of an instrument in that theme is connected to a specific disease such as diabetes, sickle cell anemia and asthma.

Conclusion: The review made it possible to know the validated instruments available to extend care to this public in health services.

Keywords

Validation Study; Child; Adolescents; Chronic Disease; Data Collect; Health Care.
1 Nursing. Doctoral student program in Decision Models, Federal University of Paraiba. Joao Pessoa, Paraiba, Brazil.

2 Teacher of the Department of Clinical Nursing, Federal University of Paraiba. Joao Pessoa, Paraiba, Brazil.

3 Master of Public Health, State University of Paraiba. Campina Grande, Paraiba, Brazil.

4 Nursing. Specializing in neonatal and pediatric nursing. Joao Pessoa, Paraiba, Brazil.

5 Nursing. Maternity Frei Damião. Joao Pessoa, Paraiba, Brazil.

6 Nursing. Master student program in Decision Models, Federal University of Paraiba. Joao Pessoa, Paraiba, Brazil.

7 Teacher of the Department of Statistics, Federal University of Paraiba. Joao Pessoa, Paraiba, Brazil.

\section{Contact information:}

Yana Balduino de Araújo.

Address: Program in Decision Models, Federal University of Paraiba. Joao Pessoa, Paraiba, Brazil.

Tel: (+55) 0839988280303.

\section{”yanabalduino@gmail.com}

\section{Introduction}

The changes in morbidity and mortality profile keep close relations with the advances in health technology, demographic and epidemiological transitions, especially in developing countries. The progressive increase in chronic diseases has generated discussions on health management scenarios for the new health needs can be met by services [1]. 
This type of disease requires the health system a high degree of complexity, proactive actions, continuous and integrated [2], besides a multidisciplinary perspective $[2,3]$ and for this it is necessary, among other actions, reorganize health service from the network configuration and use tools that support the process to ensure comprehensive care to people who are in this condition.

The quality of health care to children and adolescents with chronic diseases can increase the lifetime of these, however, this condition implies a intense relationship between the family of these individuals and the health system [4].

However, a study [5] reveals that there are weaknesses in the network of the care process both in primary care and in hospital, another aggravating factor is that the information on this public is little shared between network services.

So, both family functioning as the link and the quality of care offered by health services can impact the situation experienced by children and adolescents with chronic diseases and their families.

The use of instruments constructed and validated by researchers in the area may favor the identification of factors that require specific interventions in order to offer a differentiated care for each situation. Given the above, this study aims to conduct a survey of scientific papers dealing with the construction and validation of instruments for children and adolescents with chronic disease. This research is justified by the need to provide a scientific understanding of the tools that support the process of caring for children and adolescents with chronic diseases in many of the health care network services.

\section{Methods}

Integrative review of literature was realized in the virtual library Latino-americana e do Caribe em Ciências Sociais e da Saúde (LILACS), National Library of Medicine (PUBMED) e Scientific Electronic Library Online (SciELO).
The searches in the bases were developed thought descriptors combined among them, that was: validation studies, child, adolescent, chronic disease, data collection, all considered as descriptors on DECS and MESH. Intervals of publication and access availability to abstract filters were applied to the result in each base. It was considered the follow north question to conduct this study: which is the scientific knowledge implemented about the build and/or validation of instruments forchildren and/or adolescents with chronical disease?

As inclusion criteria, was stablished: contain as study theme questions about build and/or validation of instruments for children and/or adolescents with chronical disease as central focus and study objective; Scientific articles or other kind of research published in Spanish, English, French or Portuguese; And, of exclusion: studies which not comply with at least one of the established criteria to inclusion, repeated articles among the bases and with different languages selected to the study.

The search strategy follows the steps outlined in

\section{Figure 1.}

To operationalize the summarization of the final stage studies of the integrative review, as well as the valuation and interpretation of results and the syntheses of the knowledge, was developed an instrument-script compound by the follows items: article title, authors, year of published, language, data base, local of the study development, study type, objective, methodological characteristics (kind of validation adopted; statistical analyze used, chronical disease type discussed; age group of the children and/or adolescents), principal aspects of data analyze, relevant results and major contributions to the care of children and adolescents with chronical disease.

The 57 articles included at the final stage, were completed translated and had the instrument-script filled by four authors with the intention to ensure the eligibility of the selected studies to compose the final sample. After the complete read, 41 studies 
Figure 1. Explanatory flowchart of search strategy and selection of studies, Joao Pessoa, 2015.

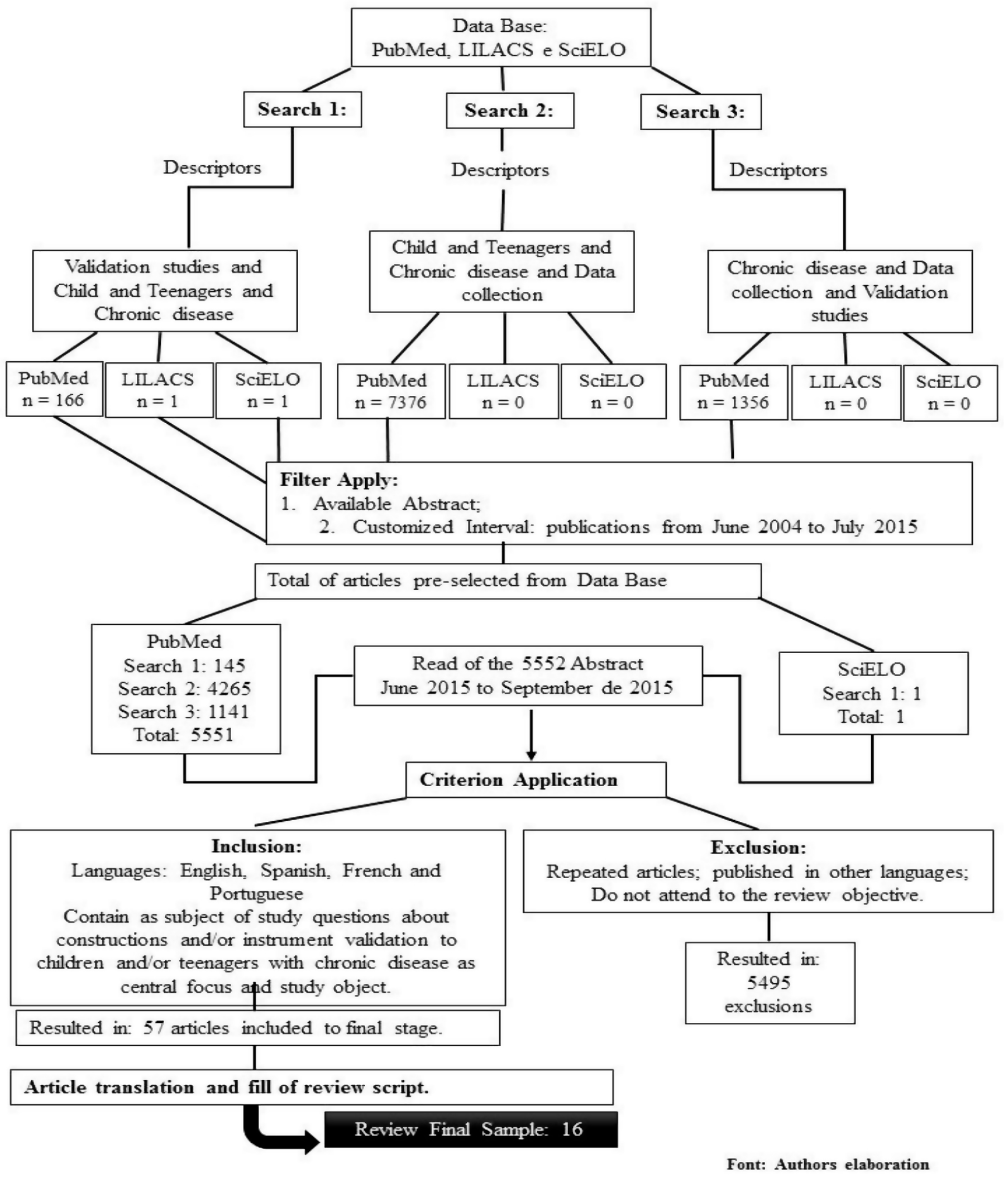


were excluded by the follow reasons: 01 was applied in neonates, 03 repeated, 08 aim the family as study objective, 17 treated the application/adaptation of scales or questionnaires already validated and 12 did not had focus in chronical disease. Thus, 16 articles compound the final sample of review and all of them were coming from PubMed data base.

\section{Results}

The following figure shows an overview of the findings. It stands out a significant number of publica- tions in North America (US and Canada) followed by European countries. As for the years of publication, there was a significant increase in interest by researchers in the area, from 2010, but the years 2012 and 2013 there was the highest number of publications, four a year on the subject.

The publications are distributed in 11 different journals, and the Health and Quality of Life Outcomes the most prominent, with 4 posts, as shown in Table 1.

Table 1. Distribution of studies on the title, authors, journal and country. Joao Pessoa, 2015.

Title

The European DISABKIDS Project: developement of seven condition-specific modules to measure health related quality of life in children and adolescents

The Bath Adolescente Pain Questionnaire (BAPQ): Development and preliminar psychometric evaluation of an instrument to assess the impact of chronic pain on adolescentes

A brief questionnaire for screening asthma among children and adolescentes in Rio de Janeiro, Brazil

Development and preliminary validation of the 'Mind the Shaw KL, Southwood TR, Gap' scale to assess satisfaction with transitional health McDonagh JE. care among adolescents with juvenile idiopathic arthritis

Cross-sectional validity of the EQ-5D-Y as a generic health outcome instrument in children and adolescentes with cystic fibrosis in Germany

Validation of a parent-proxy quality of life questionnaire for paediatric chronic cough (PC-QOL)

Reliability and validity of the Norwegian child and paren versions of the DISABKIDS Chronic Generic Module (DCGM-37) and Diabetes-Specific Module (DSM-10)

Validity and reliability of the Korean version of the pediatric quality of life ESRD module

Summarizing activity limitations in children with chronic illnesses living in the community: a measurement study of scales using supplemented interRAl items

Evaluation, modification and validation of a set of asthma illustrations in children with chronic asthma in the emergency department

\section{Authors}

Baars RM, Atherton Cl, Koopman HM, Bullinger M, Power MD.

Eccleston C, Jordan A, McCracken LM, Sleed M, Connell $\mathrm{H}$, Clinch J.

Santos MC, Cunha AA

Eidt-Koch D, Mittendorf T, Greiner W.

Newcombe PA, Sheffield JK, Juniper JF, Petsky HL, Willis C, Chang $A B$.

\section{Froisland DG, Markestad T,} Wentzel-Larsen T, Skrivarhaug T, Dahl-Jorgensen K, Graue M.

Park KS, Choo MH, Ha S, Kang HG, Cheong HI, Park YS, Lee YJ, Lee JH, Cho HY.

Phillips CD, Patnaik A, Moudouni DK, Naiser E, Dyer $J A$, Catherine $\mathrm{H}$, Fournier $\mathrm{CJ}$, Miller RT, Elliott TR

Tulloch J, Vaillancourt R, Irwin $\mathrm{D}$, Pascuet $\mathrm{E}$.
Periodicals (year, vol., $\left.n^{\circ}, p.\right)$ country where it was developed

Health and Quality of Life Outcome 2005; 3(70): 1-9. Several Europe countries Pain 2005; 118: 263-270. England

Allergologia et Immunopathologia 2005; 33(1): 20-26. Brazil

Child: care, health and development 2006; 33(4): 380 388. Union Kingdom

Pediatrics 2009; 9(55): 1-8. Germany

Thorax 2010; 65 (9): 819-823. Australia

Health and Quality of Life Outcome 2012; 10 (19): 1-11. Norway

Health and Quality of Life Outcome 2012; 10 (59): 1-7. South korea

Health Services Research 2012; 12(19): 1-12.

United States

Canadian Respiratory Journal 2012; 19(1): 26-31.

Canada 


\section{Title}

Disease activity assessment in childhood vasculitis: development and preliminary validation of the Paediatric Vasculitis Activity Score (PVAS)

\section{Authors}

Dolezalova P, Price-Kuehne FE, Annals of the Rheumatic Diseases Özen S, Benseler SM, Cabral DA, Anton J, Brunner J, Cimaz R, O'Neil KM, Wallace CA, Wilkinson N, Eleftheriou $\mathrm{D}$, Demirkaya E, Böhm M, Krol P, Luqmani RA, Brogan PA.

Dyadic Confirmatory Factor Analysis of the Inflammatory Bowel Disease Family Responsibility Questionnaire

The youth report version of the Child and Adolescent Scale of Participation (CASP): assessment of psychometric properties and comparison with parent report

PedsQLTM Sickle Cell Disease Module: Feasibility, Reliability, and Validity

Reliability and validity of PedsQL for Porguese children aged 5-7 and 8-12 years

PedsQL Multidimensional Fatigue Scale in Sickle Cell Disease: Feasibility, Reliability, and Validity

PedsQL Multidimensional Fatigue Scale in Sickle Cell Disease: Feasibility, Reliability, and Validity
Greenley RN, Reed-Knight B, Blount RL, Wilson HW.

\section{3; 72: 1628-1633. Czech}

Republic
McDougall J, Bedell, G, Wright V.

Panepinto JA, Torres S, Bendo CB, McCavit TL, Dinu B, Sherman-Bien S, Bemrich-Stolz C, Varni JW.

Ferreira PL, Baltazar CF, Cavalheiro L, Cabri J, Gonçalves RS.

Panepinto JA, Torres S, Bendo $C B$, McCavit TL, Dinu B, Sherman-Bien S, Bemrich-Stolz C, Varni JW.

Panepinto JA, Torres S, Bendo CB, McCavit TL, Dinu B,

Sherman-Bien S, Bemrich-Stolz United States C, Varni JW.
Journal of Pediatric Psychology 2013; 38(8): 871-882. United States

Child: care, health and development 2013; 39 (4): 512522. Canada

Pediatric Blood Cancer 2013; 60: 1338-1344 United States

Health and Quality of Life Outcome 2014; 14 (122): 1-8. Portugal

Pediatric Blood Cancer 2014; 61: 171-177.

United States

Pediatric Blood Cancer 2014; 61: 171-177.

Source: Research data, 2015
Periodicals (year, vol., $n^{\circ}, p$. .) country where it was developed

\section{Discussion}

The synthesis build of the selected studies in the review show that the motivation to develop an instrument or quiz in the theme of chronical is strictly linked to factors, as: handling of a specific disease such as diabetes $[6,7,8]$, sickle cell anemia $[9,10]$, asthma [7, 11, 12], chronic kidney disease [13], Cystic fibrosis [14]; children and/or adolescents family inclusion in the validation process or as subject of the instrument application [6, 10, 15, 16, 17]; measurement of subjective dimensions of life experience with chronic disease such as: quality of life [7, 13], satisfaction with care [17], chronic pain experience
[18] as well as the limitations to develop common activities [19].

The use of statistical measures as tools to support the validity, reliability and reproducibility of instruments built was present in all studies. These measures are closely related to the purpose of the study and, consequently to the type of validation (concurrent, predictive, content, appearance and convergent) of each case. Some authors $[6,13]$ used an instrument already built and validated and proceeded to translation and adaptation into another language and specific cultural context, a process known as cross-cultural validation, which translated 
an originally European questionnaire to the Norwegian and Korean version, respectively. Other studies $[6,9,13,14,15,20]$ proposed to construct and validate similar versions of existing questionnaires (concurrent and/or convergent validation) and compare the reliability of the new version with the older instrument.

Reliability can be estimated statistically by two concepts: Internal consistency, measured by Cronbach's Alpha, and temporal stability, using the coefficient of variation. The Cronbach's alpha coefficient, originally proposed by Cronbach in 1951 [21], is a measure used in psychometric instruments to assess the internal consistency of dimensions or constructs. The measure is based on the correlation of items, which compound each dimension. Authors argue that values above 0.70 indicate satisfactory internal consistency to new instruments [22].

The authors $[12,23]$ who chose to evaluate the ability of the instruments created to apply as predictors for the diagnosis of diseases such as asthma and chronic cough, they used the predictive type of validation to achieve the objectives. The content validation was used in some studies $[10,11,16,17]$ as a method to check reliability to the purpose that each instrument proposed to measure. Asthma was also cited as the target of research, in this the authors developed and validated a set of illustrations representing the asthma control levels in order to improve the care provided by parents to children. To validate the illustrations, parents, children and adolescents were participants in the study [11], the authors point out that an action plan with instructions to facilitate the communication in health, such as illustrations, can contribute to better control of the disease. Still on asthma, the authors [12] have developed a simplified questionnaire with four questions for the test diagnosis of the disease in a hospital in Rio de Janeiro. The same diagnostic test methodology was used for chronic cough in Australia [23].
Among the experiments with sickle cell anemia $[9,10]$ researchers used an already validated questionnaire called PedsQL (Pediatric Quality of Life inventory) and built a version to evaluate the fatigue caused by sickle cell anemia using the MFS scale (Multidimensional Fatigue Scale). Finally, the authors showed clinical potential and focusing the scale research of purposes to assess the severity of symptoms of fatigue [10] and said that the use of it will facilitate the understanding of health and wellbeing of children with the disease [9]. In Portugal, a version of PedsQL was also validated to be applied to children aged between 5-7 years old and 8-12 years old diagnosed with diabetes mellitus type 1 or spina bifida [8].

Using the same questionnaire about quality of life, PedsQL, authors [13] constructed and validated a module to assess this aspect in Korean children in the final stage of chronic kidney disease. Another questionnaire that aimed to measure aspects linked to quality of life was the Health Related Quality of Life (HRQoL), based on this questionnaire, was created a committee involving seven European countries in order to develop instruments to measure the quality of life of children and adolescents with different types of chronic diseases, and this project was called DISABKIDS. A module of this instrument is the DCGM-37 (DISABKIDS Chronic Generic Module-37), this module was translated [6] to the Norwegian version, in order to be used in children and adolescents with type 1 diabetes and their parents. The study results confirm that version is reliable and valid to highlight the clinical features that are important for the management of the disease [6].

A study [7] described suggestions about the construction of specific modules from questionnaires on quality of life already validated. It pointed that it must combine common features of chronic diseases in general, applying a general questionnaire, with the use of a specific module, since this process provides additional information regarding a specific disease and gives to the clinical and investigators a 
unique opportunity to compare different conditions between different countries.

Exampling a build of generic questionnaire, a study [19] exposed to physical limitations as a general factor for several chronic diseases and concluded that the information collected from the professionals and caregivers constitute a solid foundation for building an individualized treatment plan with a view to improve the health of children, in view of the limitations of each, plus the ability to integrate health information throughout the course of life of these patients.

Considering the possibility of monitoring the differences in the health status of children and adolescents with cystic fibrosis lifelong, authors [14] used a questionnaire for adults (EQ-5D EuroQol-5 Dimensions) and validated a version for children and youth. The instrument used by the authors, consisted five dimensions: mobility, self-care, daily activities, pain/discomfort and anxiety all directly linked to management of the disease.

An instrument for assessing pediatric vasculitis was also elaborated [20], according to the authors, doctors needed to assess disease activity for therapeutic decisions, evaluate the prognosis of the disease and to evaluate the feedback to treatment of different groups, however there was no instruments for children, so the researchers used a version for the adult already validated and developed a new valid version, feasible and reliable for this purpose. Already the influence of chronic pain in the psychosocial aspects of adolescents was described by a survey conducted in England [18]. The author has created and validated a unique questionnaire for clinical use and efficacy studies and effectiveness of treatments for chronic pain BAPQ (The Bath Adolescent Pain Questionnaire), the results indicate that it is possible to study the effects of pain in adolescents and develop methods to mitigate over there.

The implications and the care to chronic disease should include the family as co-responsible for the care, and it is in this perspective that an author [16] developed the household responsibility ques- tionnaire in chronic inflammatory disease (IBD-FRQ Inflammatory Bowel Disease Family Responsibility Questionnaire). In this questionnaire, dimensions are contemplated linked to disease control, such as: social aspects, nutrition, and division of tasks and maintenance of health in general. The results of the questionnaire revealed that the better management of the disease is closely related to the involvement of young people in self-care and family support to this activity. The authors also indicate that it was possible to produce an additional empirical support to know more about the family's responsibility in the condition imposed by the disease.

The participation of young people, affected by juvenile idiopathic arthritis, with self-care during the time of transition from adolescence to adulthood has been widely discussed [17]. The use of three scales involving the management of the environment, care provider characteristics and issues related to the transition process was completed by the parents and their young children. The authors pointed out that the transitional care can be considered generic aspects of other chronic diseases, and thus, the scale can be used in other contexts [17].

In a similar environment, researchers [15] with the participation of children and young people in selfcare using a CASP scale (Child and Adolescent Scale of Participation) and compared with the perception of parents. The authors affirm that it is important that these patients express their perception of their health and well-being and at the same time it is essential to compare with parental reporting by providing a rich and more complete picture of the health needs that children present.

\section{Conclusion}

This study provides the realization of a survey of instruments designed and validated for children and adolescents with chronic disease. Thus, it enable to know the validated instruments available for use during the care process to this public in various fields of health. 
The care of children and adolescents with chronic disease involves common dimensions such as family involvement, continuous contact with the health services network (specialized clinics, hospitals, primary care, etc.), the direct or indirect influence of the conditioning and determining (social, economic, cultural, environmental) and the natural course of the disease itself and itself regardless of the type of disease faced. It is up to professionals associated with the care given to this distinguished audience know involve the family as co-responsible and strengthen the network of care considering the existing dimensions in each case with a view to ensure improvements in the quality of life of these children, adolescents and their families.

The use of validated instruments can facilitate the process in order to streamline the identification of individual needs of each child/adolescent and thus contribute to the integrality care. While enabling a wide exploitation of existing instruments on the issue, the number of instruments available for use in Brazil is still restricted which may difficult its implementation in the country's health services.

\section{References}

1. Lima MF, de-Paulo LF, Higarashi IH. Technology-dependent children: the meaning of home care -a descriptive study. Online braz j nurs [Internet]. 2015 June [Cited 2015 Nov 23]; 14 (2): 17889. Available from: http://www.objnursing.uff.br/index.php/ nursing/article/view/5191. DOI: http://dx.doi.org/10.17665/16764285.20155191

2. Mendes EV. As redes de atenção à saúde. Cien Saúde Colet [Internet]. 2010 [cited 2015 Nov 23]; 15(5):2297-2305. Available from: http://www.scielo.br/pdf/csc/v15n5/v15n5a05.pdf.

3. Peterson C, SimeonssonJR, Enskär K, Huus K. Comparing children's self-report instruments for health-related quality of life using the International Classification of Functioning, Disability and Health for Children and Youth (ICF-CY). Health Qual Life Out [Internet] 2013 [cited 2015 Nov 23]; 11 (75):1-10. Available from: http://www.ncbi.nlm.nih.gov/pmc/ articles/PMC3648353/ DOI: http://hqlo.biomedcentral.com/ articles/10.1186/1477-7525-11-75
4. Cipolletta S, Marchesin V, Benini F. Family Functioning as a Constituent Aspect of a Child's Chronic Illness. J Pediatric Nurs. [Internet] 2015 [cited 2015 Nov 22]; 30(6):19-28. Available from: http://www.pediatricnursing.org/article/S08825963(15)00030-5

5. Araújo YB, Reichert APS, Lucena MGV, Collet, N. Fragilidade da rede social de famílias de crianças com doença crônica. Rev. bras. enferm. [Internet] 2013 Oct [cited 2015 Nov 26]; 66 (5): 675-681. Available from: http://www.scielo.br/pdf/reben/v66n5/06.pdf DOI: http://dx.doi.org/10.1590/S0034-71672013000500006.

6. Froisland DG, Markestad T, Wentzel-Larsen T, Skrivarhaug T, Dahl-Jorgensen K, Graue M. Reliability and validity of the Norwegian child and parent versions of the DISABKIDS Chronic Generic Module (DCGM-37) and Diabetes-Specific Module (DSM-10). Health Qual Life Out [Internet] 2012 [cited 2015 Nov 26] 10: 19. [included in the review]. Available from: http://www. ncbi.nlm.nih.gov/pmc/articles/PMC3296581/ DOI: http://hqlo. biomedcentral.com/articles/10.1186/1477-7525-10-19

7. Baars RM, Atherton $\mathrm{Cl}$, Koopman $\mathrm{HM}$, Bullinger $\mathrm{M}$, Power MD. The European DISABKIDS Project: developement of seven condition-specific modules to measure health related quality of life in children and adolescentes. Health Qual Life Out [Internet] 2005 [cited 2015 Nov 26]; 3(70):1-9. [included in the review]. Available from: http://www.ncbi.nlm.nih.gov/pmc/ articles/PMC1326227/ DOI: http://hqlo.biomedcentral.com/ articles/10.1186/1477-7525-3-70

8. Ferreira PL, Baltazar CF, Cavalheiro L, Cabri J, Gonçalves RS. Reliability and validity of PedsQL for Porguese children aged 5-7 and 8-12 years. Health Qual Life Out [Internet] 2014 [cited 2015 Nov 26]; 14(122): 1-8. [included in the review]. Available from: http://www.ncbi.nlm.nih.gov/pmc/articles/PMC4172820/ DOI: http://hqlo.biomedcentral.com/articles/10.1186/s12955014-0122-3

9. Panepinto JA, Torres S, Bendo CB, McCavit TL, Dinu B, ShermanBien S, et al. PedsQL Multidimensional Fatigue Scale in Sickle Cell Disease: feasibility, reliability, and validity. Ped Blood Cancer [Internet] 2014 [cited 2015 Nov 26]; 61:171-177. [included in the review]. Available from: http://www.ncbi.nlm.nih.gov/pmc/ articles/PMC3848797/ DOI: 10.1002 / pbc.24776

10. Panepinto JA, Torres S, Bendo CB, McCavit TL, Dinu B, ShermanBien S, et al. PedsQLTM Sickle Cell Disease Module: feasibility, reliability, and validity. Ped Blood Cancer [Internet] 2013 [cited 2015 Dec 01]; 60:1338-1344. [included in the review]. Available from: http://www.ncbi.n/m.nih.gov/pmc/articles/PMC4412167/ DOI: 10.1002 / pbc 24491

11. Tulloch J, Vaillancourt R, Irwin D, Pascuet E. Evaluation, modification and validation of a set of asthma illustrations in children with chronic asthma in the emergency department. Can Respir J [Internet] 2012 [cited 2015 Dec 01]; 19(1):26-31. [included in the review]. Available from: http://www.ncbi.nlm. nih.gov/pmc/articles/PMC3299044/ 
12. Santos MC, Cunha AA. A brief questionnaire for screening asthma among children and adolescentes in Rio de Janeiro, Brazil. Allerg et Immuno [Internet] 2005 [cited 2015 Dec 01]; 33(1):20-26. [included in the review]. Available: http://www. elsevier.es/en-revista-allergologia-et-immunopathologia-105articulo-a-brief-questionnaire-for-screening-13070604 DOI: 10.1157/13070604

13. Park KS, Choo MH, Ha S, Kang HG, Cheong HI, Park YS, et al. Validity and reliability of the Korean version of the pediatric quality of life ESRD module. Health Qual Life Out [Internet] 2012 [cited 2015 Dec 02]; 10 (59):1-7. [included in the review]. Available from: http://hqlo.biomedcentral.com/ articles/10.1186/1477-7525-10-59 DOI:10.1186/1477-7525-10-59

14. Eidt-Koch D, Mittendorf T, Greiner W. Cross-sectional validity of the EQ-5D-Y as a generic health outcome instrument in children and adolescentes with cystic fibrosis in Germany. Pediatrics [Internet] 2009 [cited 2015 Dec 3]; 9(55): 1-8. [included in the review]. Available from: http://bmcpediatr.biomedcentral.com/ articles/10.1186/1471-2431-9-55 DOI: 10.1186/1471-2431-9-55

15. McDougall J, Bedell, G, Wright V. The youth report version of the Child and Adolescent Scale of Participation (CASP): assessment of psychometric properties and comparison with parent report. Child: care, health develop [Internet] 2013 [cited 201523 Nov] (4):512-522. [included in the review]. Available from: http://onlinelibrary.wiley.com/doi/10.1111/cch.12050/epdf DOI: $10.1111 /$ cch.12050

16. Greenley RN, Reed-Knight B, Blount RL, Wilson HW. Dyadic Confirmatory Factor Analysis of the Inflammatory Bowel Disease Family Responsibility Questionnaire. J Ped Psychology [Internet] 2013 [cited 2015 Nov 24]; 38(8): 871-882. [included in the review]. Available from: http://jpepsy.oxfordjournals.org/ content/38/8/871.long DOI: 10.1093/jpepsy/jst030

17. Shaw KL, Southwood TR, McDonagh JE. Development and preliminary validation of the 'Mind the Gap' scale to assess satisfaction with transitional health care among adolescents with juvenile idiopathic arthritis. Child: care, health develop [Internet] 2006 [cited 2015 Dec]; 33(4):380-388. [included in the review]. Available from: http://www.ncbi.nlm.nih.gov/ pubmed/17584392 DOI: 10.1111 / j.1365-2214.2006.00699.x

18. Eccleston C, Jordan A, McCracken LM, Sleed M, Connell $H$, Clinch J. The Bath Adolescente Pain Questionnaire (BAPQ): Development and preliminar psychometric evaluation of an instrument to assess the impactof chronic painon adolescentes. Pain [Internet] 2005 [cited 2015 Nov 20]; 118: 263-270. [included in the review]. Available from: http://www.ncbi.nlm.nih.gov/ pubmed/16202524
19. Phillips CD, Patnaik A, Moudouni DK, Naiser E, Dyer JA, Catherine $\mathrm{H}$, et al. Summarizing activity limitations in children with chronic illnesses living in the community: a measurement study of scales using supplemented interRAl items. Health Serv Res [Internet] 2012 [cited 2015 Nov 12]; 12(19):1-12. [included in the review]. Available from: http://www.ncbi.n/m.nih.gov/pmc/ articles/pmid/22270147/ DOI: 10.1186 / 1472-6963-12-19

20. Dolezalova P, Price-Kuehne FE, Özen S, Benseler SM, Cabral DA, Anton J, et al. Disease activity assessment in childhood vasculitis: development and preliminary validation of the Paediatric Vasculitis Activity Score (PVAS).Ann Rheum Diseases [Internet] 2013 [cited 2015 Dec 3]; 72:1628-1633. [included in the review]. Available from: http://www.ncbi.nlm.nih.gov/ pubmed/23100606

21. Cronbach LJ. Coeficient alpha and the internal structure of tests. Psychometrika [Internet] 1951 [cited 2015 Dec 02]; 16(3): 297334. Available from: http://kttm.hoasen.edu.vn/sites/default/ files/2011/12/22/cronbach 1951 coefficient alpha.pdf

22. Pollit DF, Beck CT. The content validity index: are you sure you know what's being reported? Critique and recomendations. Res Nurs Health [Internet] 2006 [cited 2015 Dec 2]; 29: 489497. Available from: http://cfd.ntunhs.edu.tw/ezfiles/6/1006/ attach/33/pta_6871_6791004_64131.pdf

23. Newcombe PA, Sheffield JK, Juniper JF, Petsky HL, Willis C, Chang $A B$. Validation of a parent-proxy quality of life questionnaire for paediatric chronic cough (PC-QOL).Thorax [Internet] 2010 [cited 2015 Dec 4]; 65 (9):819-823. [included in the review]. Available form: http://www.ncbi.nlm.nih.gov/pubmed/20805179

Research funded by CNPq, Universal Notice 01/2014 (No. Process: 448716/2014-3).
Publish in International Archives of Medicine

International Archives of Medicine is an open access journal publishing articles encompassing all aspects of medical science and clinical practice. IAM is considered a megajournal with independent sections on all areas of medicine. IAM is a really international journal with authors and board members from all around the world. The journal is widely indexed and classified Q1 in category Medicine. 